\title{
Multiple osteomas of the falx cerebri and anterior skull base: case report
}

\author{
Khaled M. Krisht, MD, ${ }^{1}$ Cheryl A. Palmer, MD, ${ }^{2}$ and William T. Couldwell, MD, PhD ${ }^{1}$ \\ 'Department of Neurosurgery, Clinical Neurosciences Center, and 'Department of Pathology, University of Utah, Salt Lake City, \\ Utah
}

The authors describe a rare case of intracranial extraaxial parafalcine and anterior skull base osteomas in a 22-yearold woman presenting with bifrontal headaches. This case highlights the possible occurrence of such lesions along the anterior skull base and parafalcine region that, as such, should be considered as part of the differential diagnosis for extraaxial calcific lesions involving the anterior skull base. To the authors' knowledge, this is the first reported case of a patient who underwent complete successful resection of multiple extraaxial osteomas of the anterior skull base and parafalcine region.

http://thejns.org/doi/abs/10.3171/2015.6.JNS15865

KEY WORDS osteoma; anterior skull base; parafalcine; falx cerebri; differential; CT; oncology

$\mathrm{O}$ STEOMAS are benign neoplasms consisting of mature normal osseous tissue. They commonly arise from the long bones of the extremities. In the region of the head and neck, they are usually limited to the paranasal sinuses, facial bones, skull, and mandible., ${ }^{4,5,7}$ Their etiology is still a matter of debate. Traumatic, infective, and developmental origins have been previously proposed..$^{16}$ These lesions affect $1 \%$ of the general population, ${ }^{8}$ but intracranial osteomas are an even rarer finding, and the mechanism behind their genesis remains unclear. There have been a few reported cases of intracranial osteomas in the literature, but there has been no prior report of multiple intracranial osteomas occurring along the parafalcine and anterior skull base regions.

\section{Case Report}

History and Examination

An obese 22-year-old woman presented to an outside hospital with pressure-like bifrontal headaches that had progressively worsened over the past few years. She was first evaluated 6 years earlier, undergoing contrastenhancing MRI of the brain that disclosed a nonenhancing extraaxial T1-weighted isointense and $\mathrm{T} 2$-weighted hypointense parafalcine lesion. At her latest presentation repeat brain MRI with and without contrast enhancement revealed enlargement of the parafalcine lesion, which now measured $1.5 \times 2.0 \times 2.4 \mathrm{~cm}^{3}$, and the development of two new lesions along the anterior skull base, one measuring $0.4 \times 0.5 \times 0.4 \mathrm{~cm}^{3}$ and the other measuring $0.5 \times 0.7 \times 0.4$ $\mathrm{cm}^{3}$ (Fig. 1). Features on a CT scan of the head were consistent with heavily calcified parafalcine and anterior skull base lesions (Fig. 2). The patient was referred for examination at our institution, where she was noted to be awake, alert, and fully oriented with no neurological findings.

\section{Operation}

Given the interval growth in the parafalcine lesion, the development of 2 new lesions, and her young age, surgical intervention was advised. She underwent a right-sided high frontal parasagittal craniotomy for resection of her parafalcine and anterior skull base lesions. The dura was 

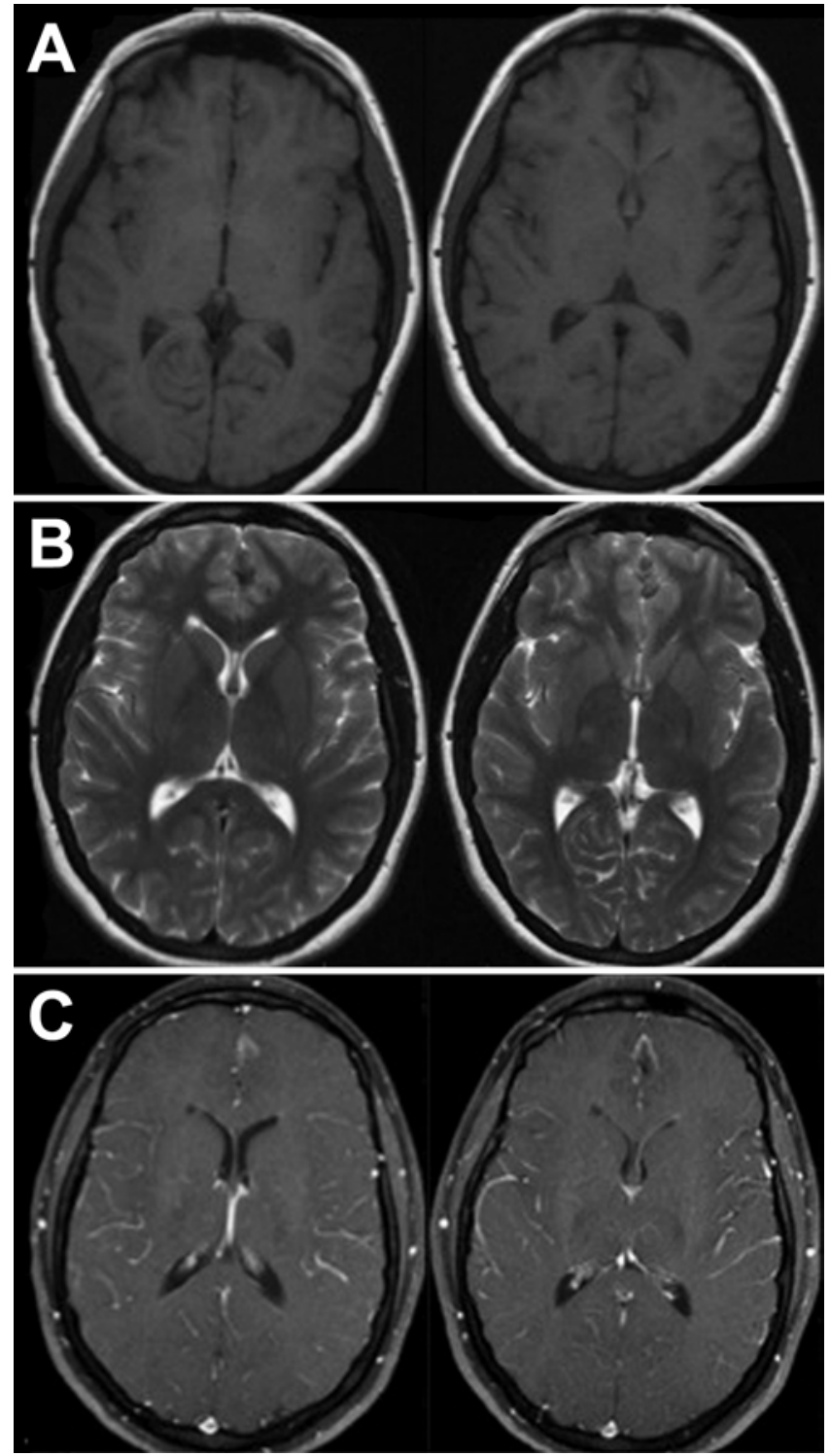

FIG. 1. Brain MRI scans demonstrating T2-weighted hypointense (A), minimally enhancing (B), and T1-weighted isointense (C) left parafalcine extraaxial lesions with minimal focal mass effect.

opened in a C-shaped fashion, with the pedicle toward the superior sagittal sinus. All 3 lesions were very firm and were resected en bloc from the surrounding brain tissue and sent for pathological analysis via permanent sections.

\section{Histological Evaluation}

Sectioning through the largest firm tissue fragment revealed finely granular, gray-brown and white bony cut surfaces. The specimen required decalcification prior to microscopy. Histological examination of sections stained with $\mathrm{H} \& \mathrm{E}$ revealed a well-circumscribed nodule of trabecular bone with unremarkable bone marrow. Portions of the marrow spaces were fibrotic. In areas, the bony trabeculae were thickened and sclerotic and displayed mild osteoblastic activity consistent with the diagnosis of an osteoma (Fig. 3).

\section{Postoperative Course}

The patient's postoperative course was uneventful. A postoperative CT scan of the head demonstrated grosstotal resection of the bony lesions with no residual. She was discharged to home on postoperative Day 2 receiving a short course of a steroid taper and exhibiting no neurological deficits.

\section{Follow-Up Visit}

The patient was seen back in clinic 3 months after surgery. She reported occasional tension headaches that responded to acetaminophen.

\section{Discussion}

Osteomas are benign neoplasms consisting of mature osseous tissue and often involve the frontal and ethmoidal paranasal sinuses. They are slow-growing lesions that

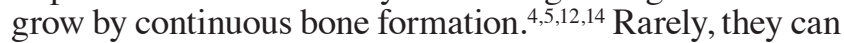
reach a diameter of greater than $30 \mathrm{~mm}$, at which stage they are referred to as giant osteomas. ${ }^{12,14}$ Most lesions, whether extra- or intracranial, are asymptomatic and are found incidentally on CT scans for an unrelated complaint of dizziness or headaches. It is very unlikely that the small lesions were the cause of our patient's headaches. Facial osteomas may cause tenderness in and around the area of involvement by stimulating subcutaneous tissue nociceptive receptors. A clear causal relationship between her headaches and these intracranial osteomas cannot be made based on our knowledge of intracranial pathology, and thus her headaches may be incidental.

The etiology of osteomas is highly debatable. Although theories relating to traumatic, infectious, and developmental causes have been proposed, there is no clear, unifying pathogenesis. Some authors believe that the inflammatory response of trauma or sinusitis may stimulate osteoblastic activity within the sinus mucoperiosteum, leading to mature bone formation. ${ }^{11,13,16}$

Histologically, osteomas are composed of trabeculae of mature lamellar bone with a fibrous stroma surrounded by osteoblasts, ${ }^{17,18}$ although long-standing osteomas may lose this osteoblastic activity. The osteoma must be differentiated from the neoplastic trabecular woven bone of parosteal osteosarcomas, which are usually separated by a cellular fibrous stroma containing mitotic figures. The latter implies a worse prognosis and has important implications for postoperative adjuvant treatment. ${ }^{18}$

When considering the differential diagnosis for osteomas, a distinctive feature on MRI is the lesions' lack of enhancement and uniform T1 and T2 signal hypointensity. ${ }^{1,19,20}$ The primary differential considerations for osteomas at the skull base are meningiomas (which usually enhance), chordomas (which are usually bright on T2weighted images), and schwannomas (which are usually bright on T2-weighted images with heterogeneous enhancement). In a more historical context, skull radiographs have been instrumental in identifying osteomas, which in various projections may help identify the location. More recently, CT has supplanted skull radiography as the preferred diagnostic method of choice. 3D CT reconstruction capabilities offer a more specific and accurate localiza- 


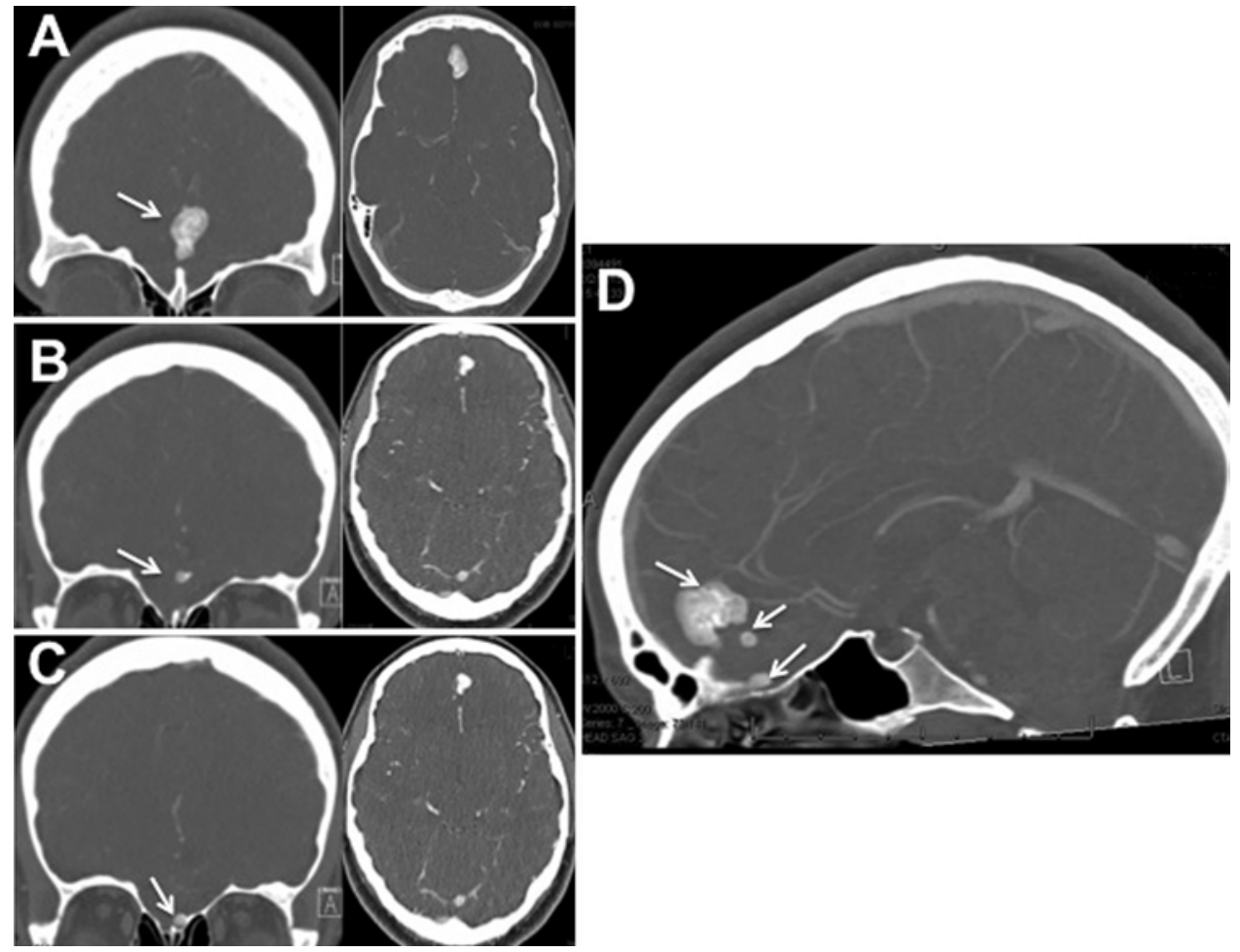

FIG. 2. Coronal and axial contrast-enhanced CT scans of the head showing 3 nonenhancing anterior frontal parasagittal hyperattenuated masses $(\mathbf{A}-\mathbf{C})$. There is no abnormal vasculature associated with these lesions. A sagittal reformatted scan showing the two parafalcine and one isolated skull base conspicuous lesions (D).

tion of the lesion with detailed delineation of its osseous morphology. ${ }^{6}$

Intracranial osteomas are extremely rare. They are usually meningeal based and arise along the convexity. ${ }^{10,13,15}$ According to Fallon et al., ${ }^{13}$ convexity meningeal-based
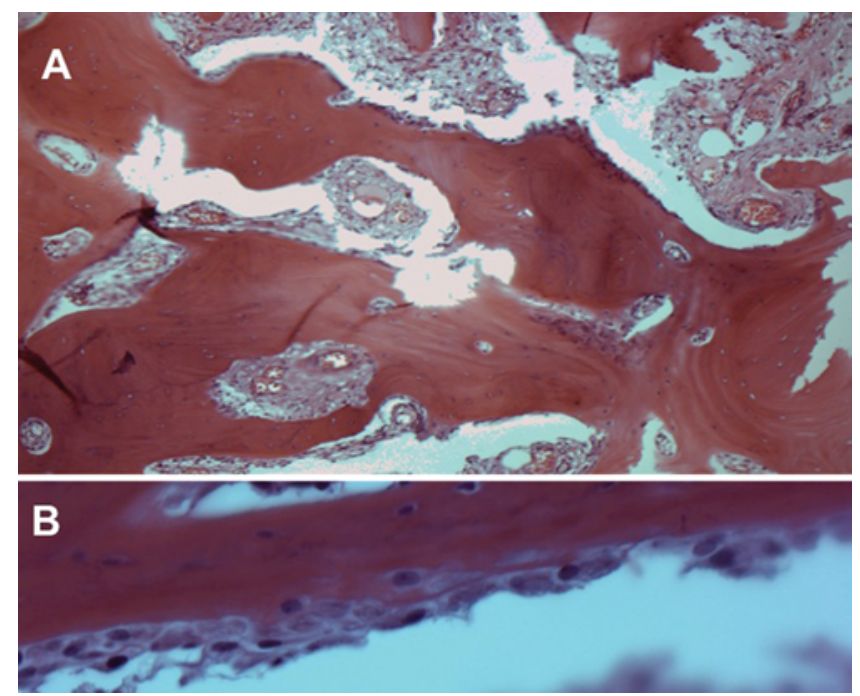

FIG. 3. Photomicrographs of $\mathrm{H} \& \mathrm{E}-$-stained sections of the bone specimen revealing lamellar bone with thickened trabecula and focally sclerotic marrow spaces $(\mathrm{A})$ and osteoclasts lining the bony trabecula $(\mathrm{B})$. Original magnification $\times 100(\mathrm{~A})$ and $\times 400(\mathrm{~B})$. Figure is available in color online only. osteomas were detected in 5\% of 200 adult autopsies, none of which involved the falx. To date, there have been 8 reported cases in the literature of patients with intracranial osteomas that were successfully treated with resection (Table 1). Seven of the cases involved a single convexity osteoma. There is only one other reported case of a solitary osteoma arising from the falx cerebri. . $3,3,9-11,21$ To our knowledge, this is the first reported case of multiple osteomas arising from both the falx cerebri and anterior skull base floor. Although the pathogenesis remains unknown, we postulate that the osteomas could arise from the anterior skull base dura and falx, since the meninges, comprising pluripotent cells, may function as periosteum. ${ }^{10,15}$ Multiple facial osteomas with supernumerary teeth and odontomas are often seen in Gardner's syndrome. ${ }^{12}$ Since our patient did not exhibit any of the other findings, as evidenced by her dental history and CT scans, this case appears to be a new and rare nonsyndromic variety of multiple intracranial osteomas.

Osteomas have a slow growth pattern, with symptoms and signs commensurate with their anatomical location if they are large enough. They have no tendency to metastasize, and complete resection when possible seems to be curative.

\section{Conclusions}

Intracranial osteomas, although rare, should be considered as part of the differential diagnosis for extraaxial lesions occurring at the anterior skull base floor. Modern- 
TABLE 1. Summary of published case reports of patients with intracranial osteomas

\begin{tabular}{lccll}
\hline \multicolumn{1}{c}{ Author \& Year } & Size $\left(\mathrm{cm}^{3}\right)$ & Age $(\mathrm{yrs})$, Sex & Presentation & Location \\
\hline Dukes \& Odom, 1962 & Not available & $60, \mathrm{M}$ & Headache & Right frontal convexity \\
\hline Choudhury et al., 1995 & $1.0 \times 1.0 \times 1.0$ & $20, \mathrm{~F}$ & Headache & Right frontal convexity \\
\hline Lee \& Lui, 1997 & $4.0 \times 2.5 \times 0.5$ & $28, \mathrm{~F}$ & Headache & Left frontal convexity \\
\hline Aoki et al., 1998 & $1.1 \times 1.5 \times 0.7$ & $51, \mathrm{~F}$ & Headache & Right frontal convexity \\
\hline Sugimoto et al., 2001 & $5.0 \times 5.0 \times 2.0$ & $35, \mathrm{M}$ & Vertigo & Right frontal convexity \\
\hline Cheon et al., 2002 & $1.2 \times 2.0 \times 0.7$ & $43, \mathrm{~F}$ & Headache & Left frontal convexity \\
\hline Akiyama et al., 2005 & Not available & $24, \mathrm{M}$ & Headache & Right frontal convexity \\
\hline Chen et al., 2013 & $2.5 \times 2.0 \times 2.0$ & $64, \mathrm{M}$ & Tinnitus w/ dizziness & Right parafalcine \\
\hline Present case & $1.5 \times 2.0 \times 2.4,0.4 \times 0.5 \times 0.4,0.5 \times 0.7 \times 0.4$ & $22, \mathrm{~F}$ & Headache & Left parafalcine \& anterior skull base \\
\hline
\end{tabular}

day imaging modalities, especially CT scanning of the head with 3D formatting, allow for early identification of these lesions. MRI is adjunctive and may help in confirming CT findings. In favorable locations that are amenable to safe removal, gross-total resection is curative. This case is the first reported account of multiple extraaxial parafalcine and anterior skull base osteomas treated successfully with gross-total resection.

\section{References}

1. Aiken AH, Akgun H, Tihan T, Barbaro N, Glastonbury C: Calcifying pseudoneoplasms of the neuraxis: CT, MR imaging, and histologic features. AJNR Am J Neuroradiol 30:1256-1260, 2009

2. Akiyama M, Tanaka T, Hasegawa Y, Chiba S, Abe T: Multiple intracranial subarachnoid osteomas. Acta Neurochir (Wien) 147:1085-1089, 2005

3. Aoki H, Nakase H, Sakaki T: Subdural osteoma. Acta Neurochir (Wien) 140:727-728, 1998

4. Bignami M, Dallan I, Terranova P, Battaglia P, Miceli S, Castelnuovo P: Frontal sinus osteomas: the window of endonasal endoscopic approach. Rhinology 45:315-320, 2007

5. Bulut E, Acikgoz A, Ozan B, Gunhan O: Large peripheral osteoma of the mandible: a case report. Int J Dent 2010:834761, 2010

6. Celzo FG, Venstermans C, De Belder F, Van Goethem J, van den Hauwe L, van der Zijden T, et al: Brain stones revisitedbetween a rock and a hard place. Insights Imaging 4:625635, 2013

7. Chen SM, Chuang CC, Toh CH, Jung SM, Lui TN: Solitary intracranial osteoma with attachment to the falx: a case report. World J Surg Oncol 11:221, 2013

8. Cheng KJ, Wang SQ, Lin L: Giant osteomas of the ethmoid and frontal sinuses: Clinical characteristics and review of the literature. Oncol Lett 5:1724-1730, 2013

9. Cheon JE, Kim JE, Yang HJ: CT and pathologic findings of a case of subdural osteoma. Korean J Radiol 3:211-213, 2002

10. Choudhury AR, Haleem A, Tjan GT: Solitary intradural intracranial osteoma. Br J Neurosurg 9:557-559, 1995

11. Dukes HT, Odom GL: Discrete intradural osteoma. Report of a case. J Neurosurg 19:251-253, 1962

12. Erdogan N, Demir U, Songu M, Ozenler NK, Uluç E, Dirim B: A prospective study of paranasal sinus osteomas in 1,889 cases: changing patterns of localization. Laryngoscope 119:2355-2359, 2009
13. Fallon MD, Ellerbrake D, Teitelbaum SL: Meningeal osteomas and chronic renal failure. Hum Pathol 13:449-453, 1982

14. Izci Y: Management of the large cranial osteoma: experience with 13 adult patients. Acta Neurochir (Wien) 147:11511155,2005

15. Lee ST, Lui TN: Intracerebral osteoma: case report. Br J Neurosurg 11:250-252, 1997

16. Mansour AM, Salti H, Uwaydat S, Dakroub R, Bashshour Z: Ethmoid sinus osteoma presenting as epiphora and orbital cellulitis: case report and literature review. Surv Ophthalmol 43:413-426, 1999

17. McHugh JB, Mukherji SK, Lucas DR: Sino-orbital osteoma: a clinicopathologic study of 45 surgically treated cases with emphasis on tumors with osteoblastoma-like features. Arch Pathol Lab Med 133:1587-1593, 2009

18. Nielsen GP, Rosenberg AE: Update on bone forming tumors of the head and neck. Head Neck Pathol 1:87-93, 2007

19. Nonaka Y, Aliabadi HR, Friedman AH, Odere FG, Fukushima T: Calcifying pseudoneoplasms of the skull base presenting with cranial neuropathies: case report and literature review. J Neurol Surg Rep 73:41-47, 2012

20. Shrier DA, Melville D, Millet D, Qian J, Millet D, Nelson C, et al: Fibro-osseous lesions involving the brain: MRI. Neuroradiology 41:18-21, 1999

21. Sugimoto K, Nakahara I, Nishikawa M, Tanaka M, Terashima T, Yanagihara H, et al: [Osteoma originating in the dura: a case report.] No Shinkei Geka 29:993-996, 2001 (Jpn)

\section{Disclosures}

The authors report no conflict of interest concerning the materials or methods used in this study or the findings specified in this paper.

\section{Author Contributions}

Conception and design: Couldwell. Acquisition of data: Krisht. Analysis and interpretation of data: Krisht, Palmer. Drafting the article: Krisht. Critically revising the article: Palmer. Reviewed submitted version of manuscript: all authors. Approved the final version of the manuscript on behalf of all authors: Couldwell.

\section{Correspondence}

William T. Couldwell, Department of Neurosurgery, University of Utah, 175 N. Medical Dr. E, Salt Lake City, UT 84132. email: neuropub@hsc.utah.edu. 